\title{
Sentipensar el pluriverso: legado del maestro Orlando Fals Borda para la sub-version, la utopia y el buen vivir
}

\author{
Feel the pluriverso: legacy of master Orlando \\ Fals Borda for sub-version, utopia and good \\ living
}

Luis Felipe Bastidas Aguilar*

\section{Resumen}

El ensayo propone la reflexión a partir de unos de los conceptos centrales del maestro Fals, el sentipensar para reflexionar acerca de la IAP, el compromiso auténtico, los valores fundantes y el socialismo raizal. Se propone que la reflexión falsbordiana tiene como característica el análisis multidimensional, donde lo racional y lo emotivo vivencial se conjugan para subvertir un orden injusto impuesto desde miradas coloniales dominantes. La propuesta, por tanto, es sentipensar la descolonización, generando una praxis liberadora de nuevas epistemologías que recogen el pluriverso opositor del pensamiento único hegemónico, impuesto por tradiciones eurocéntricas.

Palabras clave: colonialismo intelectual, IAP, pluriverso, praxis, sentipensar, socialismo raizal.

\begin{abstract}
The essay proposes the reflection from one of the central concepts of the master Fals, the sentipensar, in order to reflect about the IAP, the authentic commitment, the founding values and the raizal socialism. It argues that the falsbordian reflection has as characteristic: the multidimensional analysis, where the rational and the emotive experiential conjugate to subvert an unjust order imposed from dominant colonial glances. The proposal, therefore, is to think about decolonization, generating a liberating praxis of new epistemologies that collect the opposing pluriverse of the single hegemonic thought, imposed by Eurocentric traditions.
\end{abstract}

Keywords: IAP, intellectual colonialism, pluriverse, praxis, raizal socialism, sentipensar.

\section{(c) (1) \$ (2)}

RECIBIDO: I9 DE JULIO DE 2019 | APROBADO: 20 DE OCTUBRE DE 2019

\section{COMO CITAR ESTE ARTICULO}

Bastidas Aguilar, L. (2020). Sentipensar el pluriverso: Legado del maestro Orlando Fals Borda para la sub-version, la utopía y el buen vivir. Collectivus, Revista de Ciencias Sociales, 7(1), 63-74. DOI: https://doi.org/10.15648/Collectivus. vol7num1.2020.2532

* Magister en Gobierno y Políticas Públicas. Universidad Externado de Colombia. Facultad de Ciencias Sociales y Humanas. Bogotá, Colombia. luis.bastidas@restituciondetierras.gov.co 


\section{Introducción}

Al reflexionar sobre la sociología sentipensante, la mente se conecta inexorablemente con la Investigación Acción Participativa, con el compromiso auténtico, los valores fundantes y los pueblos originarios, el socialismo raizal, entre otras representaciones. Al visualizar la proyección de la sociología, también se hacen visibles sus orígenes, como amalgama integral y necesaria, obligando al investigador a permanecer conectado e inmerso a las raíces tanto pedagógicas: la educación popular, al igual que las causas y contextos sociales en las que el compromiso, la descolonialidad, el des-aprendizaje y las propuestas emergentes (disórganos). Por tanto, no es posible generar sentipensamiento, sin conocer el contexto territorial, los actores, las dinámicas de los conflictos, tanto la Sub-versión como la Utopía.

Este artículo pretende esbozar los aportes más representativos del maestro Orlando Fals Borda que se relacionan directamente con la sociología sentipensante y que se enmarcan en lo que el maestro Fals denomino la subversión y la utopía, análisis dirigido en un marco especial que hace eco en los pueblos andinos: el Buen Vivir. Bajo este parámetro, se incluye al final, desde algunos escenarios colectivos, la armonización de Sentipensar y las lógicas locales que se aferran al pluriverso del Sur.

\section{La sub-versión ante el colonialismo intelectual}

El contexto socioeconómico y cultural de Colombia y el resto de países latinoamericanos fueron confrontados por el maestro Fals Borda desde un análisis multidimensional, complejo, desde una óptica particular percatándose de incluir nuevas lógicas ya que el mismo trópico, amazónico como andino, requiere paradigmas endógenos, alternativos y abiertos. Para Fals Borda, el investigador circunscrito en estas realidades de la región solo puede surgir a raíz del contacto con la vida real, las circunstancias, el medio y la geografía. Por tanto, es la práctica de la endogénesis la que permite priorizar las iniciativas útiles para las sociedades y comunidades locales que permitan a su vez, identificar y priorizar alternativas de solución ante la posibilidad de superar las crisis del contexto en mención.

Sin embargo, los procesos de desarrollo económico implementados en los países latinoamericanos surgen de escenarios contradictorios y poco eficaces que provienen de preceptos positivistas y/o paradigmas funcionalistas. En estas condiciones es donde precisamente la crítica certera de Fals Borda cobra su propia dinámica y acción contra la "castración intelectual en nuestro medio y al colonialismo intelectual" a través de la Subversión (Fals Borda, 2013).

Precisamente, las consecuencias de la castración intelectual son las afectaciones al medio en el que vivimos como países tropicales, las decisiones equívocas de los gobiernos solo han incidido negativamente en el deterioro de las relaciones hombre-naturaleza; tal como lo reconoce Arturo Escobar en su libro "Sentipensar con la Tierra. Nuevas lecturas sobre el desarrollo, territorio y diferencia" (Escobar, 2014) a uno de tantos que inspiraría la sociología sentipensante:

Estos textos también se inspiran en el concepto de sentipensamiento popularizado por el maestro Orlando Fals Borda (...) Sentipensar con el territorio implica pensar desde el corazón y desde la mente, o co-razonar (...) es la forma en que las comunidades territorializadas han aprendido el arte de vivir. (...) más que con los conocimientos descontextualizados que subyacen a las nociones de "desarrollo", "crecimiento" y "economía". (p.16) 
Para este marco de análisis social, los ciclos dinámicos del medio ambiente y sus cuidados fueron aprehendidos históricamente por los campesinos y comunidades étnicas, adoptados de la Colombia rofunda ${ }^{1}$ en la que viven, quienes construyen continuamente su propio mundo, su cosmovisión y su realidad, a lo que Escobar denominaría por encima de la noción de cultura: la ontología, aquella noción que permita la existencia de otros mundos, en sí, el "pluriverso", en contraposición a la creencia de un solo mundo (equivalente al mundo globalizado, eurocéntrico, moderno/capitalista, racional) el uni-mundismo arraigado a la globalización neoliberal obstruye las posibilidades de re-existencia y de la inter-epistemología (Escobar, 2014); estas nociones que en la sociología sentipensante tienen su propia dinámica al concebirse como diversas configuraciones de conocimientos y saberes.

En esencia, la sociología que propone el maestro Fals Borda, hace visible la existencia del pluriverso y pone en entredicho el discurso de la homogeneidad intelectual (colonialismo intelectual) propio de la colonialidad del saber, y resalta en sí, al contrario, los diversos espacios para la re-existencia, a saber:

La reconstrucción de la armonía entre el hombre y la naturaleza en nuestro país obviamente implica empezar por conocer las peculiaridades del medio en el cual nos corresponde vivir. Estas soluciones no pueden entenderse ni aplicarse copiando o citando esquemas de otros contextos como autoridad suficiente, sino liberándonos de éstos con el fin de ejercer la plena autodisciplina investigativa de la observación y la inferencia. (Fals Borda \& Mora-Osejo, 2004, p.5)

El maestro Fals Borda (1978), no insistía en la urgencia de paradigmas científicos y marcos técnicos de referencia que, sin ignorar lo universal o lo foráneo, privilegien la búsqueda de la creatividad propia. No se concibe por tanto el aislamiento de la historicidad del mundo exterior pero, si es de relevancia la acumulación de conocimientos congruentes con nuestro crecimiento y progreso, que en la InvestigaciónAcción Participativa (IAP) se define como "suma de saberes" (Dykinson Salazar, 1992).

La investigación Acción Participativa incluye en su proyección, a la subversión contra el colonialismo intelectual, representa por tanto, una incidencia directa y un impacto relevante en las políticas sociales y en las decisiones institucionales que se cuentan en el marco de la resolución de conflictos sociales y de las distorsiones en la relación hombre-naturaleza, por ejemplo, dicha incidencia proporciona espacios en los que se recaban hechos, saberes y conocimientos Otros, desde una óptica, como se ha dicho, endógena. Por medio de la subversión contra el colonialismo intelectual, las políticas públicas cuentan con una herramienta que interactúa con el conocimiento propio, con la historia endógena y las realidades geográficas, que aportan recursos y capacidades humanas acorde con los valores fundantes generadores de solidaridad y robustecedores de la identidad cultural.

Para el maestro Orlando Fals Borda (2013) el concepto de Subversión no es abordado desde la connotación peyorativa La subversión por tanto, representa un proceso que logra transformaciones sociales a causa de las incongruencias del orden social en un momento histórico determinado. Es decir, la subversión implica un escenario de cambio cualitativo y cuantitativo que genera un impacto en el orden establecido de normas, representaciones y condiciones de vida de una comunidad o grupo de personas que padecen unas condiciones adversas, la IAP en ese escenario, juega un papel innovador.

\footnotetext{
1 Existe una Colombia profunda... desconocida desde la centralidad e históricamente olvidada por el Estado. Una Colombia a la que se llega después de viajar muchas horas por trochas que parecen eternas y que conducen a paraísos naturales poco explorados, donde la vida cotidiana se resuelve en el día a día con mucho menos de lo que se considera necesario en las grandes ciudades" Ver: http://www. elmundo.com/noticia/Colombia-profunda/49819; “donde la presencia del Estado es nula desde el comienzo de los siglos, ubicadas en sitios estratégicos que comunican a otros departamentos, forman parte de esa Colombia profunda que nadie visita, donde habitan los que no tienen voz" Ver: https://www.elespectador.com/opinion/opinion/colombia-profunda-columna-622128; Otras connotaciones del concepto se pueden encontrar en: http://www.cronicadelquindio.com/noticia-completa-titulo-las_mltples_caras_de_la_colombia_profunda-seccion-la_salida-nota-113299; http://prensarural.org/spip/spip.php?article22099
} 


\section{Sentipensar la descolonización}

La descolonización en América Latina tiene una marcha en particular que se relaciona con el desmontaje de los sistemas hegemónicos de dominación que imponen prácticas y comportamientos excluyentes. No basta comprimir la descolonización a un problema de igualdad que refleja más bien un concepto desgastado en la senda recorrida de la modernidad sino más bien, avanzar en la construcción de un criterio endógeno capaz brindar herramientas para superar los esquemas de la multiculturalidad avasallante. Implicaría no solo una institucionalidad que invente programas y planes de inclusión poblacional, sino más bien, la constitución de un sujeto capaz de provocar un giro histórico transformador y lleve las riendas de aquella subversión posible.

Para el avizoramiento de un proceso descolonizador, es preciso reconstituir y reconfigurar el método con el que se planea recuperar la identidad perdida y azotada. Hay que tener en cuenta que la "descolonización es un planteamiento político de construcción, no solo de crítica" (Samanamud, 2012; Monreal, Cárdenas, y Martínez, 2019), en el cual la defensa de la identidad o de identidades excluidas implica visibilizar, empoderar y construir un saber y un ser descolonizados, a partir de los principios de endogénesis, de contextualidad y de trópico (Fals Borda, 2013).

Por tanto, el primer momento del proceso descolonizador estaría constituido por escenarios que potencien la deconstrucción del conocimiento hegemónico, positivista y eurocéntrico presente en la cotidianidad de las comunidades del Sur, y más precisamente en la vida cultural de los pueblos así como en sus procesos etnoeducativos o de educación popular. Entretanto, repensar la vida social, cultural y etnoeducativa va más allá de los términos que llevan a conocer el contexto socioeconómico y los índices de calidad de vida, así como la representación culturalista, o por el contrario de elementos pedagógicos y curriculares. El escenario de la deconstrucción estaría dotado de la germinación de Pensamientos Críticos y de procesos Deliberativos que no busquen la mera oposición a la teoría sino que persistan constantemente en la armonización de una Epistemología endógena y de una nueva Ontología. Solo así, ya cabe la posibilidad de fomentar la estructura o la institución que se encargue de la acción consolidar la acción deconstructiva hacia los pensamientos "otros" y los paradigmas "otros".

La búsqueda y hallazgo de una epistemología endógena tiene como finalidad la constitución de un nuevo sujeto político que recupere el conocimiento que le permita el des-aprendizaje, el reaprendizaje y la cocreación colectiva por medio de la interculturalidad, el Pensamiento Crítico. Y para ello la interculturalidad debe también superar su versión en sospecha: la (re) validación de la cultura del otro, pero privilegiando la hegemonía de la cultura dominante. Por lo tanto, se propone un ejercicio interactivo, con la participación de actores del territorio-región, que aporte a la identificación de legados, representaciones, imaginarios y cosmovisiones desde el concepto de etnia.

\section{Praxis de la descolonización}

Lo anterior pone en evidencia la Emergencia de nuevas epistemologías sobre los contextos emergentes e históricos que suscitan (o develarían) la ausencia del Ser y del Saber (Santos, 2009). La sospecha del discurso del colonialismo intelectual es necesario para la constitución del nuevo sujeto político. Sin este requisito se corre el riesgo de perpetuar un diálogo multicultural excluyente y por lo tanto colonizador. Las iniciativas emergentes, de base, desde abajo están llamadas a desvirtuar el discurso hegemónico, androcéntrico y eurocéntrico presente en las prácticas colonizadoras del sistema económico imperante al que desde la política, le hacen eco. 
La modernidad en sus promesas de cambio, ha permeado un nuevo discurso que se plasma en el aquí y en el ahora, en los contextos próximos, emergentes de la realidad latinoamericana, y para el caso colombiano, en la coyuntura de los acuerdos de paz y posterior escenario de postconflicto (Sánchez, Pérez, Rebolledo y Rodríguez, 2019). Este nuevo discurso de la "realidad" del mundo de la Vida, centra su atención y esencia en la imposición de un conocimiento "único" pero distanciado de las lógicas de las comunidades, un conocimiento que incluye al otro, que valoriza el criterio del otro pero que legitima y privilegia, en la teoría y en la acción, el discurso hegemónico.

Su constitución como sujeto político, en lo práctico, requiere de un cambio en el pensamiento y en la concepción de la realidad. Es el pensamiento crítico el motivante (o estructurante) a nuevas perspectivas y relatos, a la mayéutica, a la indagación constante, a la deliberación, a la acción comunicativa. Pero el escenario para abordarlo y llevarlo a la praxis colectiva, exige superar los modelos eurocéntricos del aprendizaje, de la educación y de la politización. La necesidad del des-aprendizaje circunda como una primera etapa en este contexto.

\section{El desaprender}

Desaprender el conocimiento de quienes en la historia han sido catalogados como los vencedores, es en sí, la historia del colonizador y el patriarca y que significa romper con la desigualdad que se sustenta en estrategias colonizantes provenientes de organismos externos a las realidades propias guiadas por la racionalidad positivista. Una racionalidad que percibe el conocimiento como una mercancía y/o un factor de alienación.

La historia, la sociología y la filosofía moderna durante décadas no interpretaron al sujeto desde su realidad inmediata, por el contrario, ha señalado de primitivas y salvajes algunas de las formas sociales de las que hacía parte.

Para Fals Borda (1991), tanto el descolonizar como el desaprender representan praxis contextualizadas y coherentes como un requisito indispensable para la formación de un sujeto político con proyección a la transformación de su entorno. Un entorno adverso al Buen Vivir, obstructor del ser y el hacer.

\section{Propuestas emergentes: Los disórganos}

Los Disórganos son las prácticas emergentes que destacan su accionar contra de los parámetros tradicionales, positivistas y excluyentes que hacen parte de la denominación que (Fals Borda, 2013) utilizaría para complementar los contra-componentes de la realidad social y que se legitiman bajo dinámicas emancipadoras que se hacen visibles en un periodo de sub-versión como proyecto social a largo plazo: la utopía.

Pero el afianzamiento de una construcción utópica soporta la identificación (o fortalecimiento) de unos valores o creencias que condicionan las metas y principios de toda acción humana. Entre tanto, estos valores inciden en la consolidación de las normas o reglas de conducta que a su vez impactan sobre comunidades o grupos sociales y políticos. Y precisamente, el interés sobre un proyecto social a largo plazo recae sobre aquellos conglomerados que bajo una creencia, un principio, y un fin común, plantean alternativas innovadoras y emergentes: en suma, endógenas. 
Para Fals (2013), los disórganos contienen en si mimos nuevas prácticas legitimadas por valores, principios, normas y conductas cuya referencia del mundo se erige como crítica a la realidad actual y que obtienen autonomía frente al imperante Colonialismo intelectual.

\section{Sendas de endogénesis, contextualidad y trópico}

Unas de las principales fuentes que promueven el sentipensamiento de los pluriversos y la descololinalidad se enmarca en tres principios fundamentales rescatados por Fals Borda: la endogénesis, la contextualidad y el trópico.

La endogénesis acoge las energías propias y fuerzas autónomas que se dinamizan dentro de un sistema cercano, rechazando asi las visiones concebidas como totalizadoras y dominantes.

El segundo principio de Contextualidad se refiere a las pautas o al objeto de referencia que orientan la acción, es la lógica que se basa en valorar y visibilizar los aportes de un contexto geográfico e histórico en particular, pero que se posiciona fuera/contra el eurocentrismo y la racionalidad de occidente.

El tercer principio hace énfasis en el Trópico, como escenario donde germinan valores esenciales y autónomos que legitiman la defensa por el territorio y la naturaleza. Para Fals Bora el reconocimiento de los valores fundantes de los pueblos originarios permite visibilizar una realidad que supera el eurocentrismo y el colonialismo intelectual, reconocerlos apropiaría y empoderaría al investigador en su acción investigativa (Fals Borda, 2003), a saber:

$\gg$ Los indígenas y los valores comunitarios y filantrópicos, la producción colectiva, el intercambio de brazos, los resguardos, las mingas, el altruismo, el respeto por la naturaleza.

$\gg$ Los Negros con el valor de la libertad.

$\gg$ Los Campesinos con los valores antiseñoriales, de dignidad política y personal.

$\gg$ Los Colonos con los valores de la auto-organización, la convivencia pacífica, la autonomía y el autogobierno.

El sentido del conocimiento que ha estado vigente en la región latinoamericana responde a la impronta e imagen occidental que con el tiempo ha influenciado y orientado el desarrollo del saber, el hacer y el ser, excluyendo tajantemente todo tipo de prácticas empíricas, populares o autóctonas. La cuestión en definir si es o no un conocimiento científico suscita grandes y hondas reflexiones que como Quijano (Colonialidad del saber) Fals Borda (ciencia propia y colonialismo intelectual), Boaventura de Sousa Santos (Epistemologías del sur) y entre otros, Enrique Dussel (Filosofía de la liberación), han entablado en el marco de un movimiento académico y social de gran envergadura en América latina: la descolonialidad del Sur.

Orlando Fals Borda (2013) propone los principios de Endogénesis, contextualidad y de trópico como alternativa emergente teniendo en cuenta que las realidades latinoamericanas conservan sus propios procesos de socialización que son comprendidos, desarrollados y construidos bajo unos marcos de referencia originarios y fundantes enraizados en cosmovisiones, cosmogonía, usos y costumbres, prácticas, aprendizajes colectivos de la América latina profunda. Emerge revitalizado en estos parámetros el Buen Vivir.

Entre el contexto y el trópico hay energías vitales que son carcomidas por el paso del tiempo -un tiempo postmoderno, postindustrial, líquido para algunos sociólogos-, energías que es preciso, ahora más que nunca, recabarlas y visibilizar la historia, los conceptos, la ancestralidad, el arraigo sobre la naturaleza. 
El proceso de Desarrollo en Colombia no ha representado otra cosa que la imposición de modelos extranjeros sobre una base cultural y antropológica presente en el territorio pero invisibilizada por siglos, desde la conquista hasta la conformación de un Estado de Derecho, nunca ha tenido eco y asiento la cosmovisión (modelo) de quienes poblaron la geografía nacional: los pueblos originarios, por ello surge una creciente crítica hacia la conformación de las regiones, y se hace evidente la gran debilidad del Estado Colombiano que se enmarcó en un obsoleto modelo centralista de ordenamiento territorial.

Las regiones pierden entonces su imaginario unificador, su autonomía y son absorbidas por la propaganda modernizadora. El discurso de una soberanía nacional no cuenta con el reconocimiento de sus particularidades ancestrales, de sus memorables usos y costumbres, de su propia e histórica organización administrativa. Fals Borda plantea entonces, la necesidad de legitimar el poder del Estado por medio de un proceso de Regionalización, el cual busca la consolidación de varias comunidades, partiendo de sus características culturales compartidas; la suma de estas regiones autonómicas darán inicio a un nuevo tipo de República, también unitaria pero regional, concibiendo un nuevo país, un nuevo sistema organizativo nacional basado en la suma de realidades afines y endógenas, ese despertar o Kaziyadu permitiría que el Estado de Derecho avanzara en reconocer las reivindicaciones colectivas, en ser eficiente en el manejo de la autoridad y en concentrar procesos económicos y productivos más estables y rentables (Fals Borda, 2001).

\section{La ontología política del pluriverso: La subversión y la utopía}

Como ya se elucidó, el maestro Orlando Fals Borda aborda el concepto de Subversión no desde la connotación peyorativa, sino más bien como proceso que logra transformaciones sociales a causa de las incongruencias del orden social en un momento histórico determinado. Es decir, la subversión implica un escenario de cambio cualitativo y cuantitativo que genera un impacto en el orden establecido de normas, representaciones y condiciones de vida de una comunidad o grupo de personas que padecen unas condiciones que obstruyen su Buen vivir.

Desde el análisis de la sociología sentipensante existen cuatro contra-componentes de la subversión: los antivalores, las contra-normas, los disórganos y la innovación tecnológica que rechazan todo tipo de "colonialismo intelectual" (Fals Borda, 1978) y que hacen visible la utopía a partir de la acción de la subversión de lo establecido, de lo que nos rodea en el mundo de la vida, de lo ontológico.

Los diálogos de saberes bajo ciertas tendencias que desde la IAP se entrelazan y armonizan con el conocimiento propio de las comunidades, promueve el tejido que como concepto vital para los pueblos étnicos construye un espacio en el que hace palpable la comunicación entre sujeto y el Otro.

La ontología política de las luchas territoriales tiene cabida en el discurso del sentipensar, toda vez que se asume como la existencia y coexistencia de las diferentes cosmologías que transitan y se dinamizan en el mundo, tal como lo expone Escobar (2014) para quien el pluriverso, son las diferentes concepciones de lo real que se entretejen y complementan a partir de la multiplicidad de mundos y que contradice la visión moderna de la existencia de un solo mundo.

En este contexto nace y se reivindican las luchas sociales de las comunidades étnicas, que colectivamente han propuesto una nueva visión plural del mundo. La transición hacia nuevos escenarios paradigmáticos y civilizatorios recae en el escrutinio de lo "real". La ontología política hace visible las prácticas relacionales de gran vitalidad para el surgimiento o rescate del nuevo sujeto, aquel que se armoniza con el territorio 
amenazado por el postextractivismo y la crisis de la modernidad que acalla las voces a favor de sentipensar con la tierra, la territorialidad, la regionalización.

Lo ontológico por tanto, requiere el compromiso del sujeto, en su mayéutica pero principalmente en su praxis, y bajo el principio de la endogénesis (Fals Borda, 2013), la defensa del territorio y de la vida como lucha epistémica y política. Una lucha epistémica en cuanto representa la forma como se constituye el territorio, entretanto lo epistémico es una lucha por el modelo del mundo y de la forma como se quiere vivir lo ancestral con lo futuro; en dicha dinámica la desterritorialización incide en la transformación de la existencia colectiva ya que afecta el nivel de relacionalización ontológica en la forma del Ser con el territorio hacia la forma de Hacer con el mercado.

Es precisamente en dicho aspecto en el que la defensa del territorio y de la vida se configura como una lucha ontológica ya que defiende otro modelo de vida, otro concepto de lo real muy desarraigado a la materialidad del mercado. ¿Pero, qué comunidades o pueblos participan y aportan a esa lucha ontológica? ¿Como medir el impacto de sus luchas bajo el contexto reduccionista de la globalización?

Una de las primeras aproximaciones es posibilitar un cúmulo de procesos investigativos que arrojen diagnósticos cualitativos y cuantitativos al respecto, y no solo eso, y más valioso para la causa de estas luchas, será la armonización epistémica, la intervención a lo comunitario y colectivo para aportar al fortalecimiento de las pautas ontológicas y vivenciales, en cuya consolidación conceptual aporte nuevas opciones de entendimiento, relacionalidad y praxis, aunando esfuerzos bajo el principio de la contextualidad (Fals Borda, 2013).

En el contexto de la globalización, la acción devastadora de expropiar el pensamiento alternativo y crítico recorre los rincones de las comunidades subalternizadas como un fantasma, es la subversión por tanto, la herramienta que aporta elementos intrínsecos para la generación de diagnósticos reales sobre las necesidades de una comunidad.

El proyecto colonizador lanza con fuerza arrolladora el fin único de su andamiaje con el solo propósito de erigir una sola racionalidad que posibilite un escenario cerrado a todo tipo de transición, tanto en el ámbito paradigmático como ontológico ontología política (Escobar, 2014). La reducción de otros mundos, del mundo otro dirige su atención hacia los principales actores que dirigen el camino hacia la transición, los pueblos originarios, por tanto, se configuran en el principal obstáculo para el proyecto homogeneizante y colonizador en el actual contexto de la globalización.

Desde el sentipensar, el reduccionismo se evidencia en la imposición de la compresión occidental del mundo sobre el conocimiento propio y colectivo del mundo otro, sobre la epistemología que se construye en los mundos otros. Una de esas epistemologías propias es el Buen Vivir.

La perspectiva del Buen Vivir, en países como Ecuador y Bolivia, es integrada al mandato constitucional como un referente contextual y endógeno, pero en detalle, el Buen Vivir realza una oportunidad para construir colectivamente un nuevo modelo de relaciones entre los seres humanos y con la naturaleza, que fraccione con el modelo eurocéntrico de progreso lineal ascendente y desarrollista, incluido desde tiempo atrás en el marco de las "promesas" de la modernidad: el desarrollo, la libertad, el progreso. Este Buen Vivir concibe la estructuración de renovadas relaciones sociales, así como la armonización con la naturaleza desde una construcción colectiva que integre la economía, el medio ambiente, la sociedad y la cultura.

En este aspecto el Buen Vivir también concibe la justicia social como el reconocimiento de la alteridad y la otredad bajo el principio del respeto, la dignidad y la interculturalidad (Escobar, 2012). 
De acuerdo a lo que plantea Escobar, el Buen Vivir, va más allá de un proyecto cultural-político puramente indígena andino. Este también está influenciado por las corrientes críticas del pensamiento occidental y su objetivo es influir en los debates regionales y globales sobre búsqueda de alternativas desde otras cosmovisiones, racionalidades, formas de vivir y pensar, y es aquí precisamente donde confluye el monumental aporte del maestro Fals Borda ya que se revitaliza la necesidad de subvertir la colonialidad del poder, el colonialismo intelectual predominante en el mundo único de la globalización (Escobar, 2014).

Para subvertir el colonialismo intelectual, debe repensarse las representaciones de la utopía, de desarrollar una ciencia comprometida con los intereses de los sectores marginados, incentivar la denuncia política, el llamado a la investigación e intervención social desde una epistemología endógena. Y en este paraje, insistir en el compromiso autentico del investigador social fue una de las principales iniciativas de (Fals Borda, 1978).

El compromiso del investigador debe centrarse en construir escenarios en los que la incidencia de las comunidades se refleje en la proyección de acciones que promuevan cambios cualitativos y cuantitativos en el contexto que habitan; por tanto, son las comunidades (populares, étnicas, campesinas) a las que el investigador provee de protagonismo en el diseño del estudio, la recolección de la información y la discusión del manuscrito final, con el fin de armonizar a su vez, el conocimiento útil con la práctica asertiva o saber popular que proporcione herramientas para dar paso al des-aprender, que conlleve a la desalienación y permita la co-creación de nuevas relaciones sociales. Para (Fals Borda, 1995), un elemento des-estructurador de la alienación es la educación popular que genere epistemologías endógenas, contextuales y de trópico.

El Buen Vivir adquiere una relevancia crucial en la sociología sentipensante ya que confluye y se acondiciona a la crítica que Fals Borda presentaría sobre el concepto de desarrollo, un concepto de desarrollo que como se ha dicho, confluye en iniciativas propias o disórganos, en un entorno comunitario, subregional o regional. Los disórganos en un contexto local entablan equivalencias y correlaciones con los principios, valores, acciones e imaginarios de sub-versión identificados a través de la IAP. Por tanto, el Buen Vivir, armonizado con el sentipensamiento, conduce al sujeto a la elaboración de posiciones ontológicas acorde con las necesidades de su entorno próximo, a su lugar de enunciación. La IAP, posibilita una intervención transformadora, crítica y colectiva que supera la concepción instrumental de la realidad (Fals Borda, 1978).

Fals Borda (2001), propone para ello la regionalización por medio de las Regiones Administrativas de Planificación-RAP-, pero va más allá, al argumentar que en el caso colombiano, es posible la constitución de una Republica Regional en la que la descentralización jugaría un papel fundamental, que no solo se asume desde la distribución del rubro monetario asignado por la nación, sino también la consolidación geográfico-cultural de las provincias, subregiones, ETIS. En concordancia a la meta de la regionalización, Fals propone la construcción de un Socialismo Raizal, entendido como la suma de procesos endógenos que proyecten una economía armonizada con la protección del medio ambiente, una política que germine con la consolidación de un sujeto político aferrado a los valores fundantes, una cultura del trópico que valore los pueblos originarios.

El Socialismo Raizal esta intrínsecamente relacionado al "Kasiyadu", o el despertar de los pueblos, el 'actuar juntos' o el 'avanzar juntos' desde las mismas bases, que sin sorpresa alguna, hace alusión de igual forma a los planteamientos del Buen Vivir, o "Sumak Kausay" para los pueblos originarios de Bolivia, o del "Wat Usán" para el pueblo indígena Awá en Nariño, entre tanto, esta comunidad por ejemplo, asentada en la subregión de Pie de Monte, propone una contribución al mundo de la vida desde su cosmovisión originaria y los diferentes mundos: inorgánico, orgánico y social. 
Lo anterior, demuestra que el planteamiento de Fals Borda se armoniza tangiblemente con la prospectiva de los pueblos originarios y al pluriverso que se extiende, se visibiliza y se vive sobre ellos, ya sean indígenas como el pueblo Awá que al igual que Fals, conciben el fortalecimiento de usos y costumbres ancestrales, la protección, el rescate y el respeto por el territorio ancestral -KAT SASU -desde el punto de vista de su espiritualidad, cosmovisión y Ley de Origen (Programa de Naciones Unidas para el Desarrollo, 2015, p.29).

Otro caso característico está representado por las comunidades negras, por ejemplo en las subregiones de Sanquianga y de la Ex provincia de Obando en el departamento de Nariño, donde se promueve la recuperación de las prácticas culturales ligadas al manejo espacial endógeno por ejemplo, los "mentideros", concebidos como espacios para el esparcimiento, transmisión e intercambio de conocimiento ancestral. Por otra parte, consideran benéfico la pervivencia cultural ligada al uso de instrumentos musicales autóctonos como la marimba, el cununo, el bombo, el wasá, la maraca. Desde la oralidad se vislumbra un marcado interés por remembrar los poemas, las décimas y jaculatorias (Programa de Naciones Unidas para el Desarrollo, 2015, p.70).

Los integrantes de la comunidad indígena de los Pastos, por su parte, hallan significado a sus acciones a través de la minga, pieza matriz de estos pueblos sureños laboriosos, misma que permite afirmar el criterio colectivo de trabajo y el cruce de saberes y esfuerzos individuales para satisfacer las necesidades (Programa de Naciones Unidas para el Desarrollo, 2015). Se constituye en la expresión simbólica de decisiones y acciones colectivas para las comunidades del sur y puede ser un gran referente, que articulados a una lectura y apropiación de nuevos paradigmas, aporta a la crisis de legitimidad en la movilidad social.

Dos casos de particular interés en la armonización con Sentipensar el pluriverso y el Buen Vivir, se enfoca desde el territorio intercultural de Jardines de Sucumbíos (Ipiales-Nariño) quienes le apuestan al proceso denominado "Tizando, hilando y tramando memoria", con el fin de "alimentar el conocimiento de las diferentes étnias con la participación de cada una de las comunidades que integran su territorio y educar a las nuevas generaciones para la conservación del territorio y su cultura". El Pueblo Nasa, otorga mucha importancia al "KIWA THE", es decir, la autoridad mayor dentro de la comunidad, quien enseña las tradiciones, la cosmovisión, el idioma, las costumbres y la espiritualidad a las nuevas generaciones (Programa de Naciones Unidas para el Desarrollo, 2015).

\section{Conclusión}

En conclusión, Sentipensar el pluriverso requiere de un proceso que armonice las regiones, las provincias, las ETIS y las RAP, como ente cultural socio-geográfico, en los cuales, el Buen Vivir sea un proyecto de vida colectivo que aúne sendas desde el territorio, y conduzca, como orienta Fals, a realizar miradas introspectivas desde el ejercicio relacional cotidiano, lo que se traduce en des-hacernos, desaprender para reconfigurarnos desde el alterno. Caminar y tejer sendas de sentipensamiento desde el territorio, debe pasar también por una mirada comprensiva sobre aquellas opresiones sutiles que se ejercen desde distintos lugares de poder, legitimadas desde la visión individualista y depredadora, aquella que desde afuera, ha desconocido los procesos de convivencias, de resistencias y re-existencias en las comunidades, particularmente de la Colombia Profunda, infravalorando las mil y una posibilidades que los pueblos originarios han ido tejiendo en el abrazo de la memoria ancestral, en el encuentro con la palabra que da vida, aquella que recrea y armoniza el tránsito por este mundo. 
Si por alguna parte tiene que pasar la validación, el sentipensamiento del pluriverso en Colombia y en los territorios, las regiones, es por el reconocimiento del otro como parte de la existencia misma, ese otro que negado como Ser, otrora por la empresa colonial y aún hoy por las políticas neoliberales, continúa emanando su sub-versión y su utopía desde los procesos mismos de resistencia y re-existencia. De esta manera, Sentipensar el pluriverso, se traduce en procesos descolonizadores, que permiten la visibilidad de aquellos que por la no ética de la guerra, del mundo globalizado, dejaron de ser/existir.

\section{Referencias bibliográficas}

Dykinson Salazar, M. C. (1992). La investigación Acción Participativa. Bogota: Cooperativa del Magisterio.

Escobar, A. (2012). La invención del desarrollo. Popayan: Editorial Universidad el Cauca.

Escobar, A. (2014). Sentipensar con la tierra. Nuevas lecturas sobre desarrollo, territorio y diferencia. Medellín: Ediciones UNAULA.

Fals Borda, O. (1978). El problema de cómo investigar la realidad para transformarla por la praxis. Bogota: Tercer Mundo editores.

Fals Borda, O. (1995). Investigación Acción, ciencia y educación popular en los 90. La Habana, Cuba: CEAAL, Taller Internacional.

Fals Borda, O. (2001). Kaziyadu: registro del reciente despertar territorial en Colombia. Ediciones Desde Abajo.

Fals Borda, O. (2003). Posibilidades y necesidades de un socialismo autóctono en Colombia. Bogota: Cuadernos CES N². Universidad Nacional.

Fals Borda, O. (2013). Socialismo raizal y el ordenamiento territorial. Bogota: Ediciones Desde Abajo.

Fals Borda, O., \& Mohamed, A. (1991). Acción y conocimiento. Bogota: CINEP.

Fals Borda, O., \& Mora-Osejo, L. E. (2004). La superación del Eurocentrismo Enriquecimiento del saber sistémico y endógeno sobre nuestro contexto tropical. 2.

Monreal, M., Cárdenas, R., y Martínez, B. (2019). Estereotipos, roles de género y cadena de cuidados. Transformaciones en el proceso migratorio de las mujeres. Collectivus, Revista de Ciencias Sociales, 6(1), 83-97.

Programa de Naciones Unidas para el Desarrollo. (2015). Paz desde los territorios, una mirada subregional. In Agenda de Paz.

Samanamud Ávila, J. (2012). Descolonización, interculturalidad y educación. Revista América Latina En Movimiento. Retrieved from http://www.alainet.org/es/active/54308

Sánchez, S., Pérez, V., Rebolledo., y Rodríguez, R. (2019). La cultura de paz y conflictos: implicaciones socioeducativas. Collectivus, Revista de Ciencias Sociales, 6(1), 235-250. DOI: http://dx.doi.org/10.15648/ Coll.1.2019.13

Santos, B. (2009). Una Epistemología del Sur: la reinvención del Conocimiento y la Emancipación Social. Mexico: Siglo XXI. CLACSO. 
